\title{
Alfabetización fotográfica en educación artística en el tercer ciclo de Educación Primaria (España)
}

Photographic literacy in arts education at the third cycle of Primary School (Spain)

\section{Eva María Domínguez-Gómez ${ }^{1}$ \\ Claudia Sánchez-Durán² \\ Universidad de Extremadura}

\section{Resumen}

Parece oportuno, viviendo en un mundo visual, analizar la situación de la enseñanza de la Fotografía, como disciplina artística, en educación primaria.

Dos objetivos vertebran nuestro trabajo realizado en la Comunidad Autónoma de Extremadura (España): 1) conocer los contenidos sobre fotografía de los libros de texto de Expresión Plástica en el tercer ciclo de educación primaria, y 2) conocer las aptitudes del profesorado ante la Fotografía como medio de Expresión Artística. A la luz de los resultados, podremos ver que los contenidos básicos en los libros de texto, relacionados directamente con la fotografía como medio de producción artística, son muy escasos o nulos, siendo un recurso infrautilizado. Por otro lado, el profesorado, aun opinando que la fotografía es un medio atractivo, motivador e importante, apenas lo utiliza en el aula como se desprende de nuestros resultados.

Palabras Clave: Comunicación y educación, educación artística, fotografía, libro de texto, primaria.

\section{Abstract}

It seems appropriate, living in a visual world, to analyse the teaching of Photography as an art course in primary school. Two main aims guide our work, developed in the Region of Extremadura (Spain): 1) to gain insights about the contents concerning photography in textbooks of visual arts in the third cycle of primary education, and 2) to analyse the visual arts teachers' aptitudes concerning photography as a means for artistic expression. According to the results, one can perceive that the basic contents in the textbooks, related directly to photography as means for artistic production, are very scarce or none, being an underused resource. On the other hand, even though teachers think that photography is an attractive, motivating and relevant media, they do not use it in the classroom regularly.

Keywords: Communication and Education, Arts Education, Photography, Textbook, Primary School. 


\section{Fotografía: medio de expresión artística en la Educación Primaria. ¿Se emplea en el aula? ( $5^{\circ}$ y $6^{\circ}$ curso, $10-12$ años)}

Consolidada la democratización de la práctica fotográfica (Flusser, 1999; Fontcouberta, 2013 y Gilabert, 2015), siendo en la actualidad un instrumento accesible a casi todo el mundo, parece oportuno analizar la situación de su enseñanza, como medio de expresión y producción artística, en Educación Primaria.

El devenir de las tecnologías, junto con diferentes aspectos de la sociedad digital en la que nos encontramos, la ha convertido en un medio que está al alcance de todos, es consumido por casi todos y ha supuesto un cambio sustancial en la manera de expresarse y convivir (Berger, 2015; Fontcuberta, 2010; Pérez, 2015). En este sentido, cabe señalar que la producción cotidiana e indiscriminada de fotografías hace que, en la mayoría de las instantáneas, el aspecto estético del lenguaje fotográfico quede a un lado y se imponga la inmediatez del momento. En este momento de producción masiva de imágenes "se hace necesario potenciar investigaciones en las que se analicen los resultados de procesos en los que se permita al alumnado no sólo leer las imágenes, sino también producir sus propias fotografías de una forma consciente e intencional, es decir, manejando los fundamentos básicos del lenguaje de la imagen" (Rodríguez, 2014:426). En nuestra opinión, es necesario saber qué es lo que los alumnos aprenden en el aula en los diferentes niveles educativos. En este sentido, el presente trabajo pretender analizar qué se enseña sobre Fotografía a los niños y niñas del tercer ciclo de Educación Primaria en el ámbito español (6-12 años), etapa importante que cierra un ciclo de formación. Dicha investigación se ha llevado a cabo con la colaboración de maestros que imparten la asignatura de Educación Plástica en el tercer ciclo de Educación Primaria ( $5^{\circ}$ y $6^{\circ}$ curso, 10-12 años) del sistema público extremeño de educación. El trabajo de campo tuvo lugar en el año 2015 coincidiendo con el periodo de transición entre leyes educativas en España, Ley Orgánica de Educación (LOE) y Ley Orgánica para la Mejora de la Calidad Educativa (LOMCE) ${ }^{1}$.

Este estudio, aunque vertebrado desde un enfoque artístico, está íntimamente relacionado con el uso las tecnologías en entornos educativos (internet, redes sociales, uso de dispositivos móviles, pizarra digital,...) propias de la sociedad de la información en la que vivimos. La Fotografía es un medio relacionado con ámbitos científicos, profesionales y personales, que trabaja aspectos artísticos, científicos, tecnológicos y comunicacionales.

Es este aspecto polifacético de la fotografía donde radica su riqueza beneficiosa en ámbitos educativos (Brisset, 2002; Scharf, 2001). 
El tercer ciclo de Educación Primaria (10-12 años) es una franja de edad propia para el desarrollo de propuestas complejas relacionadas con los medios, pues la maduración de los niños y niñas permite realizar actividades expresivas personales y creativas, pero también, desde una posición técnicamente avanzada en destrezas manuales, "permite que el niño trate con una gama más amplia de cualidades y le permite tratarlas de forma más totalizadora en su trabajo artístico" (Eisner, 2005:104).

La materia sobre la que realizaremos este estudio es Educación Artística, área que se encuentra dividida en dos partes en el sistema educativo español: educación plástica y educación musical. Ambas se articulan en dos ejes: percepción y expresión. Nos centraremos en los aspectos expresivos que nos ofrece la Fotografía como medio para descubrir, transmitir sentimientos, observar y expresar ideas. La imagen fotográfica es un tipo de lenguaje con el cual el alumnado está familiarizado, que entiende, pero que por lo general no sabe utilizar con acierto compositivo y comunicativo (Jiménez, 2016). Una de las causas de esta carencia compositiva, entendida como "ser capaz de desplegar los dispositivos estéticos adecuados para las intenciones fotográficas de una forma deliberada, además de jovial y creativa " (Holzbrecher,2015: 385), podría tener su origen en la falta de contenidos que se imparten sobre Fotografía en la escuela. Cuestión que podremos comprobar a la luz de los resultados obtenidos en el trabajo que aquí presentamos. En este caso, centramos nuestro análisis en conocer los contenidos de Fotografía que se imparten en la asignatura de Educación Plástica, que enmarca, según la ley (LOMCE), los contenidos de educación audiovisual. Contenidos referidos al estudio de la imagen en todas sus manifestaciones, incluida la Fotografía (Real Decreto 1513/2006:43074, Real Decreto 126/2014:19402-19404).

Es nuestro objetivo principal comprobar si la Fotografía, como recurso artístico, está infrautilizada como medio de comunicación y expresión en la educación primaria, donde, como acabamos de mencionar y veremos más adelante, las directrices de alfabetización visual están presentes por ley. En este sentido, y desde una revisión previa a los libros de texto de la materia utilizados por profesorado y alumnado, observamos que los contenidos de Fotografía, en $5^{\circ}$ y $6^{\circ}$ de primaria, son escasos e insuficientes para los objetivos que marca la ley.

\section{Libros de texto y profesorado de Educación Plástica y Visual}

Para poner a prueba nuestra hipótesis, que parte de la idea de que la Fotografía es un medio infrautilizado en la materia de Educación Plástica, se han tenido en cuesta dos 
aspectos. Primero, conocer los contenidos que aparecen sobre Fotografía en los textos publicados por las editoriales de Expresión Plástica y Visual en el tercer ciclo de Educación Primaria $\left(5^{\circ}\right.$ y $\left.6^{\circ}\right)$. Segundo, conocer las aptitudes del profesorado que imparte la asignatura de Expresión Plástica, sus conocimientos y su valoración sobre la Fotografía, como medio de producción artística. De esta forma, conocer como se estructuran los libros de texto de la materia, como parte que influye en el proceso educativo, nos permitirá aproximarnos a los posibles conocimientos de fotografía a los que los alumnos tienen acceso (Llorente, E.; Andrieu, A.; Montorio, A. y Lekue, P.; 2003). Por otro lado, saber las aptitudes y actitudes del docente ante la fotografía, nos permitirá aproximarnos al enfoque que este puede dar de ella en el aula (Carballo Santaolalla, R. y Fernández Díaz, M.J. 2005).

La investigación que aquí presentamos, se ha circunscrito al ámbito regional (Extremadura); sería muy interesante, en un futuro próximo, contrastarla con un estudio más ambicioso realizado a nivel nacional. Las editoriales analizadas son empleadas en otras comunidades autónomas y la formación de los maestros, en la materia de Educación Artística, es similar en las Universidades Españolas, salvando algunas excepciones (Sánchez, 2016). Dicho esto, sería conveniente realizar otros estudios regionales que ofrecieran la oportunidad de poner a prueba nuestra hipótesis, además de presentar un panorama más representativo de la situación de la fotografía en el sistema educativo español.

Las muestras objeto de nuestro análisis serán dos: a) una selección de libros de texto de la asignatura de Plástica, del tercer ciclo de primaria, y b) el profesorado que imparten la asignatura de Plástica en $5^{\circ}$ y $6^{\circ}$ de primaria. Para el análisis utilizaremos una estrategia mixta que nos permita la recogida y análisis de datos con métodos cualitativos y cuantitativos, que faciliten un discurso descriptivo y contextualizado de los resultados obtenidos (Cook y Reichardt, 1986).

\section{a) Libros de texto y Fotografía}

En primer lugar analizaremos libros de texto de la asignatura de Educación Plástica, pertenecientes a diferentes editoriales de amplia difusión y publicados para el curso académico 2014-2015. Para ello emplearemos el método del análisis de contenido (Bardin,1986; Berelson, 1984; López, 2002) con el objeto de determinar los contenidos de fotografía que se recogen en ellos para $5^{\circ}$ y $6^{\circ}$ de primaria; para ello analizaremos los temas y las ideas que estos libros presentan para el desarrollo de la Fotografía como materia artística.

Revista Digital do LAV - Santa Maria - vol. 9, n. 3, p. 15 - 34 - set./dez. 2016 ISSN 1983 - 7348 http://dx.doi.org/10.5902/1983734822037 


\section{b) Profesorado y Fotografía}

La muestra del profesorado se configura a través de un sondeo mediante formulario on-line. Entendemos las limitaciones que este medio encierra, pero es una herramienta que permite acceder a una muestra institucional que de otra forma sería muy costosa, en tiempo y recursos. En este sentido, al no ser la educación plástica y visual una materia impartida por especialistas, se hacía necesario dirigirse a todos los maestros del sistema educativo extremeño. Por ser conscientes de esta limitación, y para enriquecer las valoraciones abiertas del formulario, creímos interesante realizar también entrevistas semiestructuradas a un grupo de profesores.

\section{Metodología de trabajo para nuestro estudio: análisis de contenido, formularios y entrevistas.}

En primera instancia, realizamos el análisis de contenido de los libros de texto. Conocer lo que los libros de texto contienen sobre Fotografía nos parecía fundamental para abordar el estudio del profesorado que, presuntamente, los podía impartir. La denominación general de todos los libros analizados es la de "libro de plástica" a pesar de que en sus contenidos aparecen unidades didácticas que trabajan tanto las competencias plásticas como las visuales. En este sentido, y para establecer una relación entre contenidos y su pertinencia según la ley, creemos oportuno comparar los resultados que se obtengan con lo que aparecen en las leyes educativas en torno a esta materia. Para ello, analizaremos la ley vigente LOE (Ley Orgánica de Educación, 2006), y la nueva ley en implantación LOMCE (Ley Orgánica para la Mejora de la Calidad Educativa, 2013) para realizar esta comparativa.

Una vez establecido el contacto con las editoriales son finalmente siete las que colaborarán y nos envían su textos escolares: Anaya (Oviedo, 2014; Oviedo, 2015), Ediciones SM (Conde y Gimeno, 2014; Conde, López, Andrada, y Gimeno, 2015), Edebé (Don-Bosco, 2014; Don-Bosco, 2015), Bruño (Montejano,, Orozco, y Chajma, 2009), Vicens Vives (Ceballos y Ruiz, 2014; Ceballos y Ruiz, 2015) Santillana (Santillana, 2014) y Sandoval (Gómez y Sandoval, 2012). Una vez recopilado los textos de nuestro estudio, definimos las unidades de análisis que serán objeto de nuestra observación. Se diseñará una plantilla con los elementos de análisis; para ello nos centramos en elementos básicos que permiten desarrollar la sensibilidad estética, la imaginación creativa y la reflexión de

Revista Digital do LAV - Santa Maria - vol. 9, n. 3, p. 15 - 34- set./dez. 2016 ISSN 1983 - 7348 http://dx.doi.org/10.5902/1983734822037 
aspectos visuales en torno a la imagen (fotografía). Esto es, punto, línea, color, textura, contorno, composición, profundidad, volumen, forma, escala, movimiento proporción y dimensión (Dondis, 1985). Además, incluimos en nuestras unidades de análisis elementos propios de la fotografía, punto de vista, encuadre, cámara fotográfica, historia de la fotografía, luz, formatos de imagen, resolución, velocidad de obturación y diafragma (Aparici y García, 1989). El análisis cualitativo y cuantitativo de estos contenidos, nos ofrece resultados que nos ayudarán a interpretar y determinar el nivel de contenidos, características y actividades que aparecen en estos textos, en relación directa o indirecta con la Fotografía. Ello, nos permite también contrastarlo con los resultados de aprendizaje provistos en las leyes educativas en materia de fotografía.

Una vez realizado el análisis de los textos, lanzamos los formularios e iniciamos el contacto con los entrevistados, hecho que nos permite profundizar en la realidad de la enseñanza de la Fotografía en las aulas de $5^{\circ}$ y $6^{\circ}$ de primaria. El formulario se envió a todos los colegios de Extremadura en varias ocasiones, con un intervalo de dos meses. Finalmente se obtuvo la colaboración de 22 maestros/as. No obstante, en la configuración de la muestra encontramos ciertas limitaciones. Por un lado, no poseer contacto directo con el profesorado, hecho que nos obliga a enviar el formulario a través de la dirección o la secretaría de los centros. De otro lado, la masificación que existe actualmente de formularios online, como método de recopilación de datos, hace que la herramienta pierda efectividad entre el profesorado que ante la saturación de solicitudes opta por no participar.

Para el diseño del formulario se contó con profesorado e investigadores del área de didáctica de la expresión plástica de la Universidad de Extremadura, que validó el documento final que se empleó ${ }^{2}$. Dicho formulario se compone de 10 cuestiones breves que nos permite ubicar al profesorado y medir el uso de la fotografía en el aula de plástica, también, la valoración que hace el profesor de la Fotografía como medio de expresión artística. Algunas de las preguntas eran: ¿Trabajas la Fotografía como recurso de expresión artística en el aula?, si trabajas la Fotografía en el aula ¿utilizas otro material didáctico a parte del libro? o caparece el tema de la Fotografía en el libro de texto que utilizas?. Para enriquecer los resultados obtenidos en los formularios, se realizaron 9 entrevistas semiestructuradas (Cáceres Reche, Hinojo Lucena y Aznar Díaz, 2011), que introducen valores cualitativos a nuestro estudio. Los docentes entrevistados fueron 9 mujeres de una edad media de entre 35 y 45 años. La muestra es heterogénea, algunas son tutoras, otras no, y algunas son especialistas en inglés, aunque actualmente imparten clases de plástica. Las entrevistas nos ofrecen una valoración directa de la Fotografía como medio y de su 
uso, o no, por parte del profesorado: conocimientos, aptitudes, opinión personal, beneficios e inconvenientes. Sus respuestas nos darán una visión más cercana de la realidad docente, que se adentra o no, en el mundo de la Fotografía como recurso didáctico.

Primero expondremos los resultados obtenidos del análisis de contenido de los libros de texto, en segundo lugar los resultados del formulario realizado a los maestros que imparten educación plástica y por último resumiremos lo conseguido con las entrevistas realizadas al profesorado. Una vez descritos los resultados pasaremos a su discusión y a exponer las conclusiones finales.

\section{¿Qué hay sobre Fotografía en los libros de texto de educación plástica y visual de $5^{\circ}$ y $6^{\circ}$ de primaria?}

Tras una revisión general de los libros de texto, se observa una ausencia generalizada en la mayoría de ellos de contenidos propios de la Fotografía. Para poder cuantificar esta ausencia realizamos el análisis de contenido; empleamos para ello la ficha de análisis que nos permitirá detectar los elementos básicos relacionados, directamente o indirectamente, con la Fotografía. En la figura 1 quedan reflejados los resultados en cuanto esto elementos básicos. El color y la textura son los elementos básicos que aparecen en todas las editoriales analizadas, con un $100 \%$ y a este dato, le sigue el punto y la línea con un 91,7\%. La composición y la luz son contenidos que aparecen por igual, un 83,3\%. Por el contrario, los elementos fundamentales y específicos de la Fotografía (velocidad de obturación y diafragma) apenas aparecen (8,3\%), aunque paradójicamente sí encontramos elementos relacionados con la imagen en general, con un $83,3 \%$ de contenidos encontrados que podrían estar relacionados de alguna manera con la Fotografía dependiendo del enfoque del maestro en el aula. 


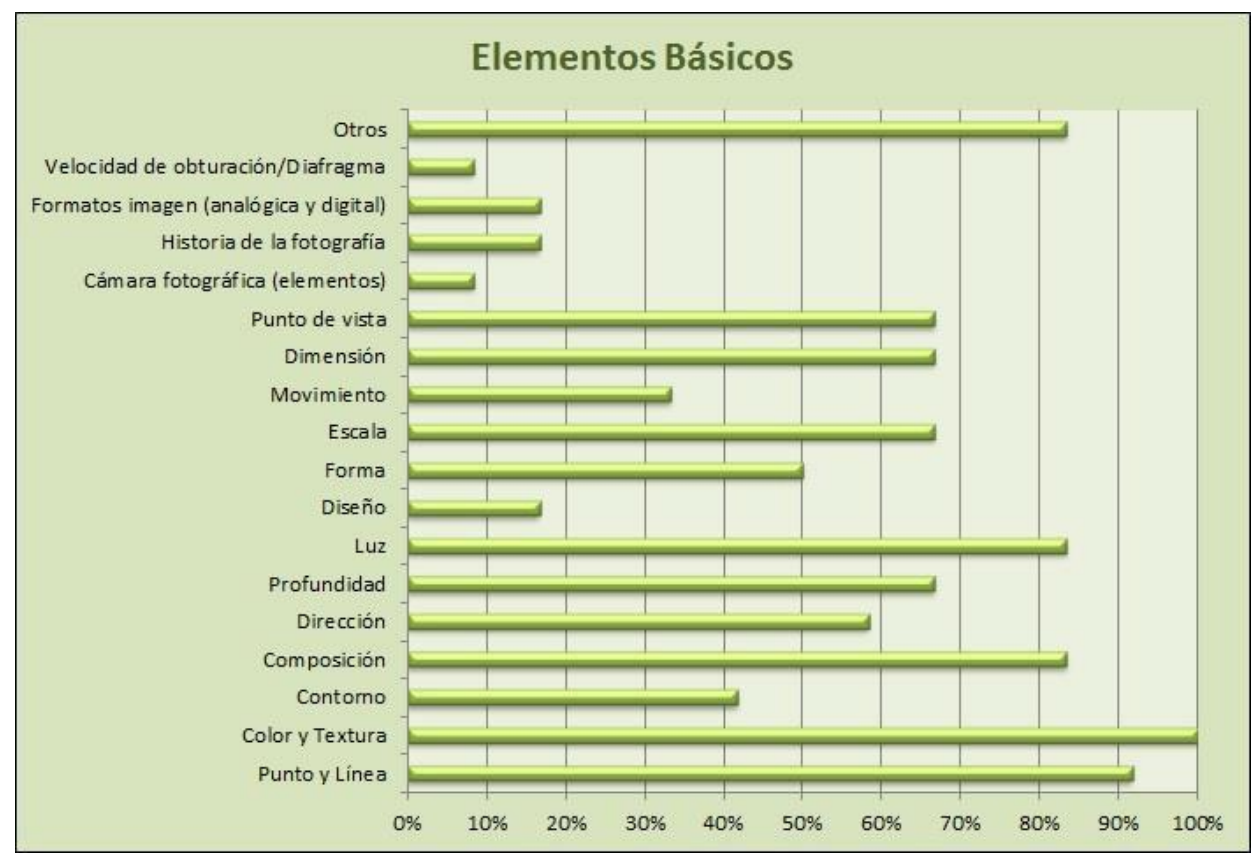

Figura 1: Resultado del análisis de los elementos básicos que aparecen en los textos.

Cuando analizados el índice temático de los textos, tan solo una de las editoriales, Bruño, dedica un tema exclusivamente a la Fotografía como expresión artística. En dicho tema denominado "Sonría, por favor", aparecen los conocimientos básicos sobre Fotografía, como velocidad de obturación, diafragma, como es una cámara fotográfica y emplearla. En el resto de editoriales aparece algunos conceptos de Fotografía de forma parcial, incluido en otros temas, o bien conceptos básicos generales del lenguaje visual que podrían asociarse a la Fotografía o no.

Por otro lado, extraemos los contenidos sobre Fotografía que reflejan las leyes educativas vigentes para la educación primaria (Figura 2). Contrastando ambas parte, libros de texto y leyes, podemos decir que: en cuanto a la LOE (Ley Orgánica de Educación), en general los textos analizados cumplen con los contenidos que están recogidos en la ley, pues estos son muy amplios y generalistas, en ningún momento se hacen mención explícita la Fotografía pero sí trabajan la imagen en otros ámbitos más tradicionales como la pintura. El contenido más relacionado, dentro del bloque de expresión y creación artística, que se recoge en la LOE, es "Empleo de tecnologías de la información y la comunicación para el tratamiento de imágenes, diseño y animación, y para la difusión de los trabajos elaborados" (Real Decreto 1513/2006: 43074).

Por otra parte, en la LOMCE (Ley Orgánica de Mejora y Calidad de la Enseñanza) no se reflejan contenidos pero sí estándares de aprendizaje evaluables, entre los que 
destacamos: "Conoce la evolución de la fotografía del blanco y negro al color, de la fotografía en papel a la digital, y valora las posibilidades que ha proporcionado la tecnología. Reconoce los diferentes temas de fotografía. Realiza fotografías, utilizando medios tecnológicos, analizando posteriormente si el encuadre es el más adecuado al propósito inicial" (Real Decreto 126/2014:19402). En esta ley materia se divide en dos módulos: A) Educación Plástica y B) Educación Musical. Dentro del módulo A se dividen tres bloques: educación audiovisual, expresión artística y dibujo geométrico. Los estándares de aprendizaje sobre fotografía, antes mencionados, se encuentran dentro del modulo de educación audiovisual (Figura 2). En este sentido, tenemos que decir que los contenidos de los libros analizados no se corresponden con lo recogido en la ley, donde sí se hace mención explícita de la Fotografía como medio, no tanto de expresión artística pero si de comunicación visual. Por último, cabe señalar que la LOMCE introduce una novedad con respecto a la $L O E$, que puede tener serias repercusiones negativas en la alfabetización homogénea en medios. Con esta ley, la educación artística pasa de ser una materia obligatoria a ser específica, esto significa que es elegible por los centros y las comunidades autónomas entre otras materia.

CONTENIDOS EXPLÍCITOS SOBRE FOTOGRAFÍA EN LAS LEYES EDUCATIVAS DE EDUCACIÓN PRIMARIA

\section{LOE}

\section{Bloque 1. Observación plástica}

Análisis y valoración de la intención comunicativa de las imágenes (TIC)

\section{Bloque 2. Expresión y creación plástica}

TIC para el tratamiento de imágenes, diseño y animación.

\section{LOMCE}

\section{Bloque 1. Educación Audiovisual}

- Reconoce imágenes fijas y en movimiento (tamaño, formato y elementos básicos como puntos, rectas, planos, colores, iluminación...)

- Conoce la evolución de la fotografía de blanco y negro al color, de la fotografía en papel a la digital, y valora las posibilidades que ha proporcionado la tecnología.

- Reconoce los diferentes temas de la fotografía.

- Realiza fotografías, utilizando medios tecnológicos, analizando y posteriormente si el encuadre es el más adecuado al propósito inicial.

Figura 2. Contenidos explícitos sobre fotografía en las leyes educativas.

\section{Fotografía y el profesor de Educación Plástica y visual}


Han respondido a la encuesta un total de 22 profesores/as, $68 \%$ de la provincia de Badajoz y el $32 \%$ restante de la provincia de Cáceres.

Pasamos a exponer los resultados de las 8 cuestiones realizadas que están directamente relacionadas con el uso de la fotografía en el aula.

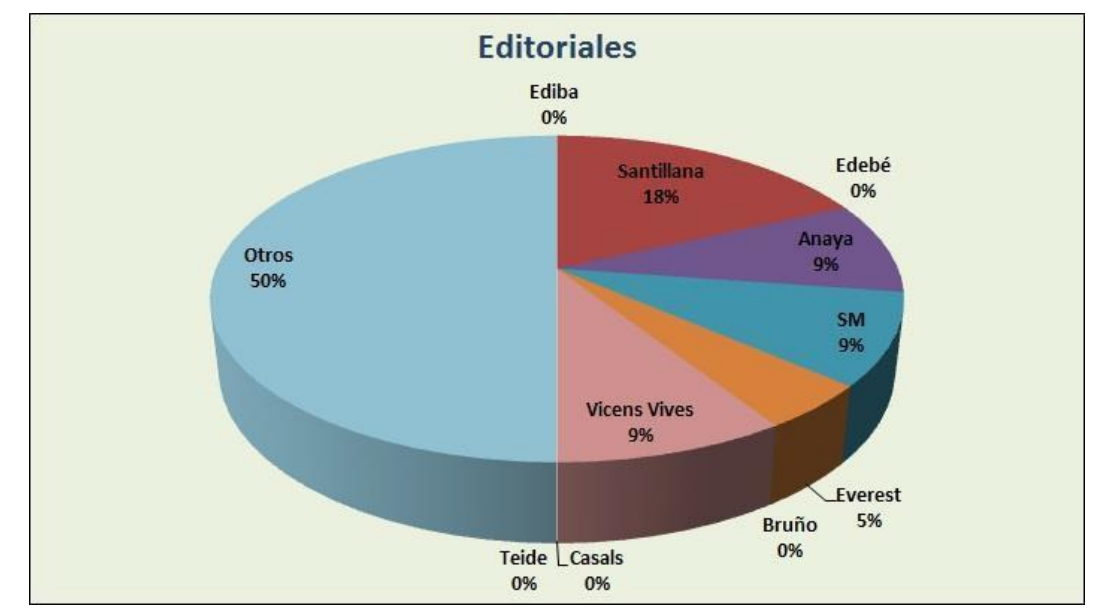

Figura 3. Editoriales utilizadas por el profesorado en expresión plástica y visual

¿Qué editorial utilizas como libro de texto en la asignatura? Ante esta pregunta la mayoría del profesorado consultado, 50\%, optó por la opción de otros, opción que recoge el uso de manuales propios, editoriales diferentes a las propuestas y otros recursos diferentes a manuales de texto. De las 10 editoriales propuestas se emplea el manual de Santillana con un 18,2\%, con un $9,1 \%$ se emplean el de Anaya, SM y Vicens Vives y con menor porcentaje, le sigue la editorial Everest, 4,5\%. Y sin embargo, las editoriales Ediba, Edebé, Bruño, Casals y Teide aparecen como no empleadas por la muestra de profesorado (Figura 3).

¿Sigues fielmente el libro? En coherencia con los resultados de la pregunta anterior, en esta cuestión predomina el profesorado que no sigue un libro con un 54,5\%, de los que siguen un libro tenemos un $36,4 \%$ que lo hace frecuentemente y un $4,5 \%$ que lo utiliza algunas veces.

¿Aparece el tema de la Fotografía en el libro de texto que utilizas? De los profesores que utilizan libro un $68,2 \%$ nos informan que la fotografía no aparece como tema en el libro que utiliza, el resto un 31,80\% confirma que sí aparece como tema (Figura 4). 
¿Trabajas la Fotografía como recurso de expresión artística en el aula? Aclaramos en esta cuestión que nos referimos al empleo artístico, creativo o plástico, no como apoyo visual de contenidos. En este sentido, tan solo el 36,4 \% del profesorado emplea la Fotografía como recurso artístico en el aula siendo la mayoría, un $63,6 \%$, los que no usan este medio para la expresión artística. A los profesores que emplean la Fotografía como medio de expresión y producción artística se les pregunta cuántas clases de plástica dedican en el curso a trabajar con este medio. El porcentaje más alto, un 55,6\%, dedica un promedio de 2 a 5 clases para este tema, un 33,3\% dedica algo más de tiempo entre 5 y 8 clases y un $11,1 \%$ dedica más de 8 clases (Figura 5 ).

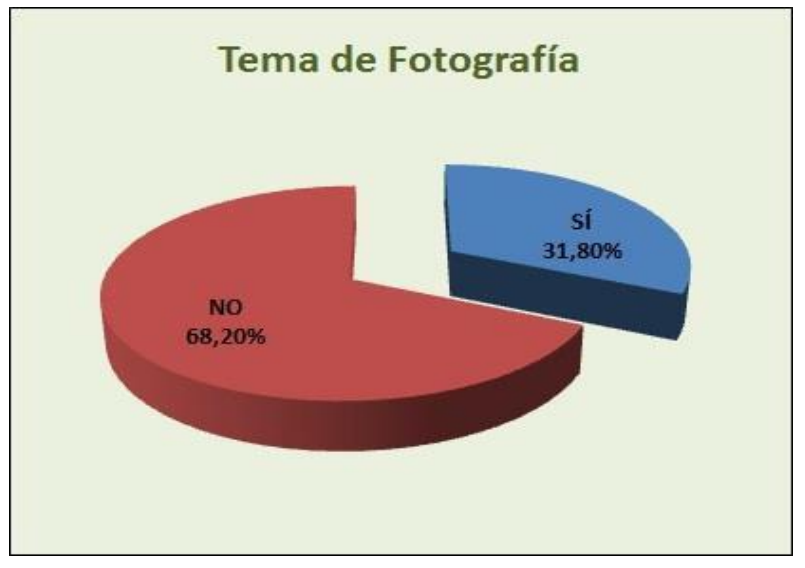

Figura 4. Gráfico sobre la aparición del tema de fotografía

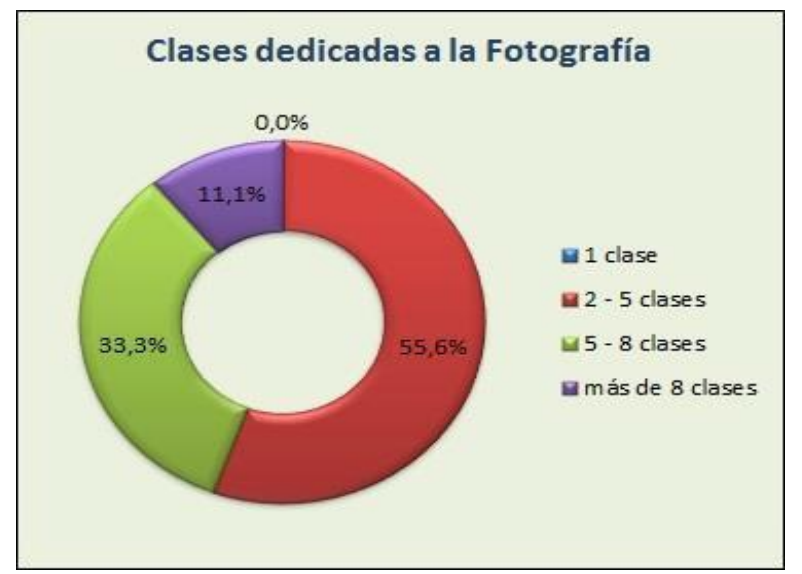

Figura 5. Gráfico de las clases dedicadas a las fotografía en expresión plástica y visual

A la pregunta abierta de ¿qué otros materiales utilizas a parte del libro? Gran parte de las respuestas estaban relacionadas con las TIC, uso del ordenador, imágenes obtenidas a través de internet, uso de cámaras fotográficas, empleo de vídeo tutoriales de fotografía a través de YouTube, revistas especializadas, materiales de elaboración propia, apuntes de cursos de fotografía y en un par de profesores invitaban a especialistas de fotografía al aula para mostrar sus trabajos y experiencias.

Además de la Expresión Plástica y Visual, ¿en qué otras materias se utiliza la Fotografía? A lo que un $36,4 \%$ contestó que no empleaban la Fotografía en ninguna otra materia, un porcentaje similar, un $31,8 \%$ la empleaban en lengua extranjera, ciencias sociales, ciencias naturales, y lengua castellana y literatura, obteniendo porcentajes poco representativos matemáticas con un $8,7 \%$ y educación física con un 13,6\% (Figura 6). 


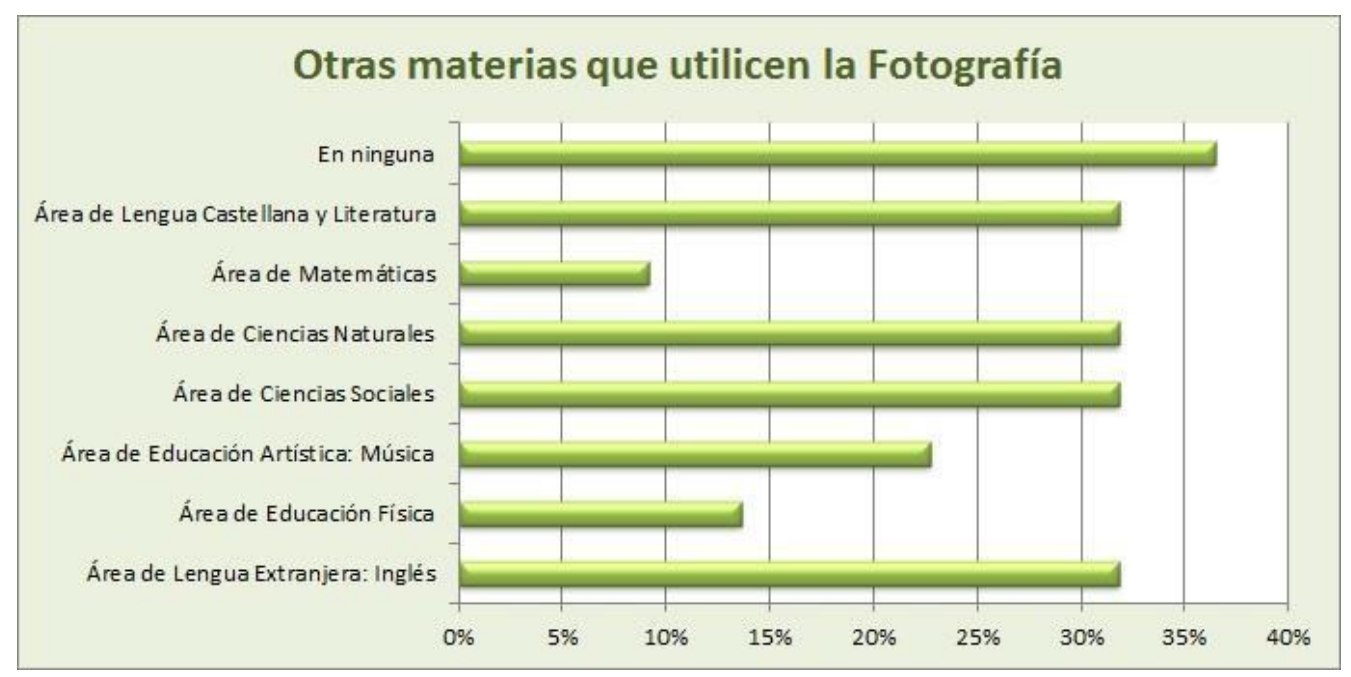

Figura 6. Gráfico de otras materias seleccionadas que aparezca la fotografía.

En la última pregunta del formulario queríamos recoger la opinión del profesorado, sobre la utilización de la de la Fotografía como medio expresivo y facilitador de nuevas posibilidades para la docencia. El $86,4 \%$ respondió positivamente confirmando sus beneficios y bondades como medio de expresión. Algunas de las justificaciones añadidas a esta cuestión se podrían resumir de la siguiente forma. Trabajar con Fotografía es motivador, tanto para el alumnado como para el profesorado. Por otro lado, ayuda a conocer y a desarrollar la faceta artística del alumnado, desarrollando competencias relativas a la imaginación y la creatividad, además centra el foco de atención del alumnado de forma amena y sencilla.

Para enriquecer esta última pregunta del formulario fueron muy útil las entrevistas realizadas. Los entrevistados fueron 9 maestras de expresión Plástica y Visual, del tercer ciclo de Educación Primaria de colegios públicos extremeños. Una de las cuestiones que nos interesaban era conocer si el profesorado utilizaba o no la Fotografía como herramienta de expresión artística. Pasamos a exponer los resultados más relevantes de las entrevistas. Las maestras nos ha permitido hacer públicos sus nombres, por ello aparecen en el texto, haciendo la redacción más fluida.

Todas las maestras, exceptuando Mila, no han usado la Fotografía como herramienta didáctica, por lo tanto, trataremos de analizar esta decisión mayoritaria.

¿Cómo valoran actualmente los conocimientos y aptitudes que tienen con respecto a la Fotografía?. Según Carmen, Irene, Mercedes, Ma Carmen y Petry, tienen un nivel básico. En cambio, Ana ha realizado cursos de fotografía. 
Victoria opina que la cámara fotográfica es un medio muy útil para los niños y la valora positivamente. Por el contrario, Ma Carmen piensa que al no ser un tema que no aparece en la programación, lo considera complicado para enseñárselo a los niños/as.

Como último matiz, Ana, Ana Isabel, Mercedes y Petry nos han confirmado que no son maestras especialistas en plástica, sino en inglés, y que circunstancialmente están impartiendo esta asignatura.

¿Qué opinas sobre los beneficios o inconvenientes del uso de la Fotografía en el aula?. Todas piensan que la Fotografía tiene más beneficios que inconvenientes. Ana Isabel opina que es un tema que puede llegar a gustar bastante al alumnado; Victoria piensa que da muchas posibilidades porque lo considera una manifestación artística y Petry está de acuerdo con estas opiniones, aportando que en educación no hay que tener límites. La Fotografía también es considerada como elemento motivador para el alumnado, afirma Victoria.

Con respecto a si la Fotografía conlleva más trabajo o preparación de las clases, Carmen piensa que conlleva más trabajo al ser conceptos que el profesorado no maneja del todo, en cambio, Victoria opina que no conllevaría trabajo sino que, al contrario, ayudaría a la materia. Petry añade que el que conlleve trabajo o no depende sólo y exclusivamente del docente. Antes de introducir la Fotografía en un aula determinada, el docente debe tener unos conocimientos básicos y necesarios para poderlo impartir, afirma Irene, Ana Isabel y Ma Carmen.

Preguntamos si en un futuro, estas maestras tendrían en cuenta la Fotografía como herramienta didáctica en plástica. La mayoría afirma que sí lo podrían tener en cuenta. Ana Isabel y Petry remarcan que el profesorado debe estar formado en este tema para impartirlo. En este sentido, nos han llegado a proporcionar ejemplos de cómo lo llevarían a cabo; Ana con un proyecto, Irene por medio de varias sesiones y $\mathrm{M}^{\mathrm{a}}$ Carmen opina que solo lo tendría en cuenta si la programación se lo pudiese permitir. No obstante, todos estas aportaciones dependerían de varios factores. El más destacado sería el de los medios económicos y recursos necesarios que pudiera proporcionar el centro. En cambio, Carmen, Victoria, Ana Isabel y Ma Carmen, opinan que depende de uno mismo, de la formación del profesorado y su interés.

Algo que nos interesaba saber eran las facilidades que ofrece el centro para el aprendizaje de la Fotografía, a través de proyectos, actividades creativas, etc. Según Ana, Carmen, Ma Carmen y Petry piensan, que en un futuro, si se llevara a cabo un proyecto 
relacionado con la Fotografía sí que lo apoyaría, sin ningún problema, pues los centros escolares están abiertos a cualquier propuesta novedosa que beneficie la educación del alumnado.

Algunos impedimentos, según Ana e Irene, son que sus centros no disponen actualmente de recursos económicos suficientes para emprender proyectos de este tipo. Por otro lado, la Fotografía sí que se utiliza como apoyo visual en varios centros como nos informan Ana Isabel, Ma Carmen y Mercedes.

En cuanto a la formación del maestro, sobre Fotografía, la mayoría de las maestras creen que si los docentes saben de Fotografía no ha sido gracias a los estudios universitarios, sino a cursos de especialización que se ofrecen en los centro de recursos y formación del profesorado. Ma Carmen nos añadió que la Universidad de Educación a Distancia también proporciona cursos de especialización en el tema, ella realizó un curso de Fotografía. Ana opina que la carrera de magisterio, ha sido y cree que aún sigue siendo, más teórica que práctica. Irene, Victoria, Ana Isabel, Ma Carmen y Petry no dieron nada de Fotografía en los estudios universitarios. Carmen nos informa que durante sus estudios, dio algunas nociones básicas de Fotografía. Mercedes, tuvo una materia denominada "Manualidades" donde sí que les enseñó Fotografía, especialmente laboratorio de revelado fotográfico, pero era un caso aislado motivado por el gran interés de la profesora que impartía la materia.

Mila es la única maestra que sí utilizaba la Fotografía como medio de expresión artística. Con respecto al alumnado, los beneficios que nos proporciona son el desarrollo creativo y la capacidad artística. También nos añade que ayuda a fijar la atención y desarrolla la observación. Respecto al profesorado, fomenta la motivación y también centra su atención. Los recursos que utiliza para la Fotografía son el libro de plástica, basado en el pintor y fotógrafo Sorolla, tutoriales en Internet sobre Fotografía, la cámara fotográfica, murales, presentaciones, etc. En su centro escolar lleva a cabo un proyecto de Fotografía "Dulce Mirada". Esta maestra ha ido aprendiendo a la vez que sus alumnos y ha descubierto un medio estupendo para la producción artística. También trabaja otros temas relacionados con la Fotografía, como informar a los niños y niñas sobre los peligros de las redes sociales y el uso de la Fotografía. Cuando trabaja la Fotografía en sus clases, nos aclara, cada maestro/a tiene su programación, con lo cual, no coinciden en las actividades. 
A la luz de los resultados obtenidos, en el análisis de los textos y la descripción del perfil del profesorado, pasamos a detallar la discusión y conclusiones de la presente investigación.

\section{Libros de texto y leyes educativas (LOE/LOMCE) para el aprendizaje de la Fotografía como práctica artística.}

Tras el análisis de los libros de Plástica empleados en esta investigación, encontramos un predominio de medios y procedimientos clásicos para la impartición de la materia como son el dibujo, la pintura y la escultura. No encontramos, por lo tanto, contenidos que hablen de la Fotografía de una forma específica y concreta, exceptuamos la editorial Bruño que dedica un tema específico a esta materia como medio de expresión artística: "Sonría por favor" (Montejano, Orozco, y Chajma, 2009:75-86), partiendo de sus elementos básicos y el lenguaje fotográfico. En esta unidad explica conceptos específicos como: la fotografía analógica, los elementos de la cámara fotográfica, la historia de la fotografía, el mensaje fotográfico, fotógrafos y estilos fotográficos. Los textos analizados han cumplido con lo recogido hasta ahora en la LOE, por la ambigüedad en los contenidos de Fotografía en esta ley, pero no han cumplido, por lo menos en su primer año, con los estándares de aprendizaje recogidos en la LOMCE. Ley en la que sí aparecen, de manera explícita, la necesidad de contenidos sobre fotografía para el desarrollo de las competencias en la producción fotográfica entre niños y niñas del tercer ciclo de educación primaria. Los contenidos recogidos en las editoriales analizadas no son suficientes, ni ofrecen el apoyo para que el maestro pueda desarrollar en el alumnado las competencias necesarias de esta herramienta artística dentro del aula. En este sentido, dado que el libro de texto es una herramienta muy empleada en el sistema educativo, insistimos en la pertinencia de introducir contenidos propios de Fotografía que sirvan de ayuda a los procesos de enseñanza aprendizaje de esta materia en la educación reglada.

Así, cabe señalar, que dado el proceso reciente de implantación de la LOMCE, sería conveniente realizar en breve un nuevo estudio para analizar los materiales editados en esta materia. No obstante, podemos intuir, que el paso del tiempo no garantice cambio de contenidos en los materiales publicados, pues se da la siguiente situación. Aun siendo la LOMCE una ley que apoya la educación en medios, la asignatura de Educación Plástica, materia específica, es elegible por los centros y las comunidades autónomas, tal y como ya se ha comentado. Esto implica pérdida de peso de la asignatura en el currículo de primaria, por ejemplo, podría ocurrir que un centro no la imparta en favor de otra materia. En este contexto, puede que las editoriales enfoquen sus energías en trabajar más los contenidos

Revista Digital do LAV - Santa Maria - vol. 9, n. 3, p. 15 - 34- set./dez. 2016 ISSN 1983 - 7348 http://dx.doi.org/10.5902/1983734822037 
de materias troncales que de materias específicas, aunque esto formula otra tesis que tendrá que ser investigada en un futuro. Lo que sé se puede afirmar después de este estudio es que, en los textos analizados no aparecen contenidos relacionados con la Fotografía, tan solo en una editorial, sin embargo, en la LOMCE sí aparece conceptos explícitos de Fotografía en los resultados de aprendizaje, para el tercer ciclo de primaria en la materia de Educación Artística.

\section{Profesorado que enseña, no enseña o podría enseñar Fotografía como práctica artística en el aula de primaria}

En cuanto al profesorado y la fotografía, los resultados nos dicen que un $63,6 \%$ no utiliza la Fotografía nunca como recurso expresivo y artístico, pero sí que usan la imagen como apoyo visual, tanto en la asignatura de Plástica como en otras. Esta idea, además, se ve reforzada cuando la gran mayoría de los maestros y maestras encuestados $(83,6 \%)$ considera este medio como muy beneficioso para su uso en el aula, incluso en las entrevistas valoran la Fotografía como una técnica muy interesante, que puede posibilitar las manifestaciones artísticas y también la caracterizan como elemento motivador de cara al alumnado. Es aquí donde nos encontramos ante una situación paradójica, en la que el maestro estima altamente los beneficios de un medio pero no lo emplea, por variados motivos no hemos registrado por no ser objeto de nuestro análisis. Diez años después aun estamos en una situación similar a la que plantea Tejedor (2006:33) "a pesar del fuerte impacto que las nuevas tecnologías están teniendo en las nuevas generaciones, todavía percibimos que los profesores más jóvenes tienen escasos conocimientos sobre aspectos tales como: mantenimiento de redes locales, uso de cámaras de fotografía y vídeo digital, utilización de equipos de audio, etc.".

A la luz de los resultados obtenidos, parece que la situación no ha cambiado mucho desde 2006, a pesar de que los docentes hayan aprendido, de una forma u otra, a manejar los medios de comunicación siguen sin implementarlos en las aulas, en nuestro caso en el aula de plástica, espacio muy apropiado para el desarrollo artístico de la Fotografía. En las entrevistas realizadas, la mayoría de las maestras reconocen tener un nivel básico respecto a la materia de Fotografía. Sólo tres maestras tienen cursos de fotografía, esto les hace tener una valoración muy positiva hacia el medio y les facilitan su uso en el día a día. Por otro lado, también ha quedado reflejada cierta actitud de rechazo hacia el uso de esta herramienta, principalmente proveniente de la escasez de conocimientos por parte del docente ya que algunas entrevistadas consideran que la Fotografía debería impartirla una persona con suficientes conocimientos en la materia. En este sentido, también se ha 
dejado ver la necesidad de una formación específica en el área de plástica en la formación inicial del profesorado, ya que algunas de las entrevistadas se han considerado no especialistas en la materia, cuando realmente no existen especialistas en el área en la Universidad Española. Muchas de las entrevistadas buscan apoyos externos para usar este medio como expresión artística en el aula, tal como medios económicos, apoyo del equipo de dirección del centro, horarios, formación, etc., cuando realmente no son imprescindibles, basta con cierta inquietud de actualización. Ejemplos aislados del uso de la Fotografía en el aula son cada vez más frecuentes y algunos los podemos encontrar en la red (Rubio, 2015), similares al de una de las maestras entrevistadas "Dulces miradas", pero no son muchos, tal vez por no abordar el desarrollo de competencias que deberían generase en la formación inicial del maestro, tal y como se desprende de las entrevistas. En este sentido, aunque de forma transversal, podemos concluir que existe una necesidad latente de especialización entre el profesorado y no solo en conocimientos sobre fotografía, sino en un amplio abanico de conocimientos en medios y expresión visual, tal y como defiende Sánchez (2016) en su trabajo sobre las carencias formativas en expresión plástica en el grado de educación primaria.

Desde el punto de vista de la docencia, en el tercer ciclo de Educación Primaria, podemos concluir que la Fotografía es un medio de la expresión artística infrautilizado en el aula de Expresión Plástica, en los colegios que ha formado parte de nuestro estudio; situación probablemente extrapolable a otros colegios a nivel regional y nacional, pues la formación de los maestros ha sido y sigue siendo muy estandarizada en el territorio nacional, salvo excepciones minoritarias. Por otro lado, nos ha sorprendido positivamente la buena valoración que el profesorado tiene de la Fotografía para la docencia, cuestión que nos parece muy valiosa y que posibilita el camino para en un futuro abordar la actualización de los docentes en esta materia.

\section{Conclusiones finales y nuevas líneas de investigación que se abren en torno al aprendizaje de la Fotografía en el aula de primaria}

Para finalizar, podemos concluir que el uso de la Fotografía como medio de expresión artística, dentro de la asignatura de Expresión Plástica y Visual, no está generalizada en los cursos analizados dentro de la comunidad autónoma de Extremadura. Por otro lado, si las editoriales siguen trabajando la alfabetización visual solo desde enfoques y procedimientos clásicos de la imagen, muy difícilmente la Fotografía aparecerá como contenido concreto de expresión artística en la programación o plan de cualquier centro. El que no aparezcan temas específicos de Fotografía en los textos de primaria, tiene consecuencias en los 
procesos de enseñanza aprendizaje, haciendo que el profesorado no la considere como medio de expresión artística dentro del aula, a pesar de que la Fotografía esté recogida en la LOMCE como estándar de aprendizaje.

Creemos que estas razones son suficientes para revisar, detallar, aclarar e interpretar mejor los contenidos de la Educación Plástica en la Educación Primaria, partiendo de las leyes educativas y su interpretación por los centros, siguiendo con la mejora de la formación del profesorado y la inclusión de la Fotografía como materia o tema específico dentro de la Expresión Plástica.

Seguimos estando de acuerdo con Porcher (1977) en que la enseñanza de la Fotografía en el entorno educativo es un tema pendiente desde hace tiempo, pues seguimos dejando esta educación a otras instancias sociales que realizan esta función de forma empírica, sin metodología o sistema, "aprender lo que es una fotografía, cómo se fabrica, se lee, cómo se mira,...nos parece que corresponde en particular a la educación primaria" Porcher (1977: 9).

Una vez concluido este trabajo de investigación surgen nuevas incógnitas. Entre ellas, profundizar en los motivos que paralizan al profesorado para el uso de este medio en el aula, si, tal y como hemos podido comprobar, es un medio bien considerado y motivador para ambas partes. Tal vez, profundizando en los motivos que causan esta contradicción, podamos aportar soluciones que potencien el uso de la Fotografía como recurso artístico en el aula.

También, nos parece oportuno revisar, una vez implantada la LOMCE en todos los niveles educativos, los contenidos y los manuales editados que se imparten sobre Fotografía, no solo en el tercer ciclo de primaria, sino también en el resto de niveles educativos. Sería muy interesante realizar estudios similares al que aquí presentamos, en las diferentes comunidades autónomas, para poder obtener inferencias que nos permitieran establecer estudios comparativos.

\section{Agradecimientos:}

Agradecemos a los maestros y maestras del sistema educativo extremeño que han colaborado desinteresadamente en esta investigación y a las editoriales que nos han facilitado el material para su análisis. 


\begin{abstract}
NOTAS
${ }^{1}$ La LOMCE es la ley de Educación Española que ha tenido una irregular implantación en las diferentes Comunidades Autónomas Españolas, por las críticas que ha suscitado en su diferentes aspectos. No obstante, la LOMCE no establece una nueva ley de educación propiamente dicha sino que modifica la anterior (LOE). El trabajo aquí presentado se realiza dentro del proceso de implantación de la LOMCE, que aun está teniendo lugar. En el curso académico 2014-2015, en el sistema extremeño de educación, en el curso de $5^{\circ}$ se había implementado la LOMCE y en el de $6^{\circ}$ no. Convivían ambas leyes. No obstante, esta transición no afecta al estudio que aquí presentamos por tratarse de un problema de fondo en los contenidos de una materia vigente en ambas leyes aunque de forma diferente. Enlace al Boletín del Estado donde se puede consultar la ley https://www.boe.es/boe/dias/2013/12/10/pdfs/BOEA-2013-12886.pdf

2 Enlace del formulario empleado:

https://docs.google.com/forms/d/e/1FAIpQLSeVkxP0CiNgJSKDQ_dme2QpKv_qgE9N2haPVab2Uo2gIPtr1g /viewform

33 Leyes educativas que convivían en el periodo de realización de este trabajo (2014-2015).
\end{abstract}

\title{
Referencias:
}

APARICI, R.; GARCÍA MATILLA, A. (1989) Lectura de imágenes". Madrid: Ediciones de la Torre. BARDIN, L. (1986). El análisis de contenido. Madrid: Akal.

BERELSON, B. (1984). Content analysis in communication research. New York: Hafner Press. BERGER, J. (2015). Para entender la fotografía. Barcelona: Gustavo Gili.

BRISSET, D. (2002). Fotos y cultura: Usos expresivos de las imágenes fotográficas. Málaga: Servicio de Publicaciones de la Universidad de Málaga.

CÁCERES, M. P., HINOJO, F. C. y AZNAR, I. (2011). Incorporación de las TIC en el período escolar de 0 a 6 años: diseño de una entrevista para evaluar las percepciones de los maestros. Pixel-Bit. Revista de Medios y Educación, 39, 7-16. Recuperado de: http://goo.gl/f7DrP4 CARBALLO SANTAOLALLA, R. y FERNÁNDEZ DÍAZ, M.J. (2005) La actitud del profesorado de Primaria y Secundaria de la Comunidad de Madrid ante las TIC problemática y claves para su integración. Actas del XII Congreso Nacional de Modelos de Investigación Educativa: págs. 235-242

CEBAlloS, I. y RUIZ-ESPINO, R. C. (2014). Aula Activa, Plástica, 50 Educación Primaria. Barcelona: Vicens Vives.

CEBALlOS, I. y RUIZ-ESPINO, R. C. (2015). Aula Activa, Plástica, 60 Educación Primaria. Barcelona: Vicens Vives.

CONDE-MIRANDA, J. F. y Gimeno, E. (2014). Savia, Plástica, 50 Educación Primaria. Madrid: Grupo SM.

CONDE-MIRANDA, J. F., López-Salán, F., Andrada, J. y Gimeno, E. (2015). Savia, Plástica, 60 Educación Primaria. Madrid: Grupo SM.

COOK, T. D. y Reichardt, CH. S. (1986). Métodos cualitativos y cuantitativos en investigación educativa. Madrid: Ediciones Morata.

DON BOSCO (Ed.). (2014). Plástica, $5^{\circ}$ Educación Primaria. Barcelona: Edebé.

DON BOSCO (Ed.). (2015). Plástica, $6^{\circ}$ Educación Primaria. Barcelona: Edebé.

DONDIS, D.A. (1985). La sintaxis de la imagen. Barcelona: Gustavo Gili.

EISNER, E. W. (2005). Educar la visión artística. Barcelona: Paidós Ibérica.

FONTCUBERTA,J.; PARR,M.; KESSELS, E.; CHÉROUX, C \& SCHMID, J. ( 2013 ) $\square$ From here on. La Postfotografía en la era de internet y la telefonía móvil. Barcelona: RM VERLAG

FONTCUBERTA, J. (2015). La cámara de pandora : La fotografía después de la fotografía. Barcelona: Gustavo Gili.

FLUSSER, V. (1999) Una filosofía de la fotografía. Madrid: Editorial Síntesis.

GILABERT, M. (2015). Kairós, el instante decisivo. Thémata. Revista de filosofía (51) pp: 227246 Doi: $10.12795-8365$

GÓMEZ-MARTÍNEZ, O. y DE-SANDOVAL, M. (2012). Plástica, Educación Primaria, 30 ciclo. Santander: Sandoval

GRUPO SANTILLANA (Ed.). (2014). Educación Plástica, 5a Educación Primaria. Madrid:

Santillana Educación

Revista Digital do LAV - Santa Maria - vol. 9, n. 3, p. 15 - 34- set./dez. 2016 ISSN 1983 - 7348

http://dx.doi.org/10.5902/1983734822037 
GRUPO SANTILLANA (Ed.). (2014). Educación Plástica, 6a Educación Primaria. Madrid: Santillana Educación

HOLZBRECHER, A. (2015). La fotografía en la educación mediática: su papel en la labor educativa (extra) académica. Profesorado. Revista de Currículum y Formación del Profesorado, 19(1), 380-394. Recuperado de: http://goo.gl/p1tXHK

JIMÉNEZ LÓPEZ, I. (2016). Análisis de la fotografía en el entorno familiar y escolar de niños de educación infantil a través de su producción fotográfica en el aula. (Trabajo fin de máster sin publicar). Universidad de Extremadura, Cáceres.

LEY ORGÁNICA DE EDUCACIÓN (LOE) (Ley Orgánica 2/2006, 3 de mayo). Boletín Oficial del Estado, no 106, 2006, 3 mayo.

Ley orgánica para la mejora de la calidad educativa (LOMCE) (Ley Orgánica 8/2013, 9 de diciembre). Boletín Oficial del Estado, no 295, 2013, 10 diciembre.

LLORENTE, E.; Andrieu, A.; Montorio, A. y Lekue, P. (2003). Análisis de libros de texto de Expresión Plástica y Visual de Educación Primaria. Revista de Psicodidáctica (14) p.p. 149-160 LÓPEZ NOGUERO, F. (2002). El análisis de contenido como método de investigación. XXI, Revista de Educación, (4)167-179.

MONTEJANO, D., OROZCO, T. M. y CHAJMA, J. F. (2009). Lapiceros, Plástica, $5^{\circ}$ Educación Primaria. Madrid: Bruño.

MONTEJANO, D., OROZCO, T. M. y CHAJMA, J. F. (2009). Lapiceros, Plástica, 60 Educación Primaria. Madrid: Bruño.

OVIEDO-MELGARES, A. T. (2014). Aprender es Crecer, plástica $5^{\circ}$ Educación Primaria. Madrid: Anaya.

OVIEDO-MELGARES, A. T. (2015). Aprender es Crecer, plástica $6^{\circ}$ Educación Primaria. Madrid: Anaya.

PÉREZ-DAZA, J. (2015). Fotografía en tiempos de darwinismo tecnológico. Aularia: Revista Digital de Comunicación, 4(1), 9-14. Recuperado de https://goo.gl/WYj79B

PORCHER, L. (1977). La fotografía y sus usos pedagógicos. Buenos Aires: Kapelusz.

Real decreto por el que se establece el currículo básico de Educación Primaria (LOMCE) (Real decreto 126/2014, 28 de febrero) Boletín Oficial del Estado, no 52, 2014, 1 de marzo.

Real decreto por el que se establecen las enseñanzas mínimas de la Educación primaria.

(LOE) (Real decreto 1513/2006, 7 de diciembre) Boletín Oficial del Estado, no 293, 2006, 8 de diciembre.

RODRÍGUEZ-HOYOS, C. (2015). La fotografía en educación: una revisión de la literatura en cuatro revistas científicas españolas. Fotocinema. Revista científica de cine y fotografía,10, 407-431. Recuperado de http://goo.gl/P4RrHK

RUBIO, M. (2015) La fotografía en Educación Primaria. Proyecto Capturando Emociones. Recuperado de

http://goo.gl/LsLsmd

SANCHEZ-GORDO, P. (2016). Estudio sobre las expresiones plásticas y su didáctica en el Grado de Educación Primaria en la Universidad de Extremadura (Trabajo fin de máster sin publicar), Universidad de Extremadura, Cáceres.

SCHARF, A. (2001). Arte y fotografía Aaron Scharf. Madrid :Alianza Editorial.

TEJEDOR, F.J.T., y Muñoz-Repiso, A.G.V. (2006). Competencias de los profesores para el uso de las TIC en la enseñanza. Análisis de sus conocimientos y actitudes. Revista española de pedagogía, 64, 21-43. Recuperado de http://goo.gl/b8QEgR

1Departamento de Didáctica de la Expresión Musical, Plástica y Corporal, Facultad de Formación del Profesorado. Profesora Contratada Doctor.

2Departamento de Didáctica de la Expresión Musical, Plástica y Corporal Facultad de Formación del Profesorado. Alumna de Doctorado.

Enviado em: 29 de abril de 2016.

Aprovado em: 25 de novembro de 2016.

Revista Digital do LAV - Santa Maria - vol. 9, n. 3, p. 15 - 34 - set./dez. 2016 ISSN 1983 - 7348 http://dx.doi.org/10.5902/1983734822037 